\title{
Stem Bark Extract from Alstonia boonei attenuates Cholesterol, Triglyceride and Oxidative Damage via Low Immunohistochemical Expression in Small Intestinal Tract of Male Rats
}

\author{
Akintunde Jacob Kehinde $^{1 *}$, Ajiboye John Adebayo², Soyinka O Oluwadamilola ${ }^{2}$ and Adeyemi A Arinola ${ }^{2}$ \\ ${ }^{1}$ Toxicology and Safety Unit, Department of Environmental Health Sciences, College of Medicine, University of Ibadan, Nigeria \\ ${ }^{2}$ Department of Chemical Sciences, Biochemistry Unit, College of Natural and Applied Sciences, Bells University of Technology Ota, Ogun State, Nigeria
}

\begin{abstract}
Stem bark extract of Alstonia boonei (SBEAB) was reported to possess anti-lipidemia, anti-microbial, antiinflammatory and anti-hypercholesterolemia properties in folk lore medicine. The present study examined the effects of SBEAB on some key lipid profiles in diabetic induced rats. Biomarkers of lipid damage, histological and immunohistochemical method were used. The expression level of cyclooxygenase (COX-2) and inducible nitric oxide synthase (iNOS) were also determined. SBEAB administered orally at dose of $200 \mathrm{mg} / \mathrm{kg}$ for 14 days significantly lowered the levels of cholesterol, triglyceride and malondialdehyde induced by single intraperitoneal administration of streptozotoxin (STREP) $(80 \mathrm{mg} / \mathrm{kg}$ ) and preserved the integrity of intestinal villi. In addition, SBEAB reduced the STREP-induced elevated activity of CAT with concomitant repression of COX-2 and iNOS expression in the intestine of diabetic rats. The protective effect of SBEAB was compared to that of metaglomide (METAG), anti-diabetic drug. Pre and post-treatment are better to prevent pro-inflammatory response and intestinal cancer in diabetic rats than METAG-administration. Taken together, the inhibition of genes programming COX-2 and iNOS expression suggest the molecular mechanism for small intestinal tract protection by SBEAB and further advocates the links between the mal-absorption of cholesterol in diabetic patients.
\end{abstract}

Keywords: SBEAB; Anti-lipidemia; Anti-inflammatory; Diabetics; Rat

\section{Introduction}

High cholesterol level was recently discovered as a principal culprit behind various life threatening diseases like hypertension, cardiovascular diseases, atherosclerosis, obesity, hypercholesterolemia, metabolic syndrome, and even diabetes [1]. Cholesterol administration has been reported to influence hepatic lipid metabolism in mammals [2]. Hypercholesterolemia is usually characterized by both abnormal serum and hepatic triglyceride and cholesterol levels [2]. As such, increase serum total cholesterol caused impairment in the triglyceride metabolism leading to the accumulation/deposition of free fatty acids in the liver, thus triggering a condition known as fatty liver [2]. This expanded liver fatty acid pool leads to increased mitochondrial and peroxisomal $\beta$-oxidation, which produces reactive oxygen species. This may, in turn, promote a local pro-inflammatory state leading to progressive liver injury $[3,4]$

Diabetes mellitus (DM) is one of the major causes of world morbidity and mortality and a common risk for cardiovascular diseases [5]. Previous study reported that diabetes mellitus is a metabolic disease characterized by hyperglycaemia resulting from defects in insulin secretion, insulin action, or both [6]. Complicated hyperglycaemia results from an absolute deficiency in insulin secretion (insulindependent diabetes mellitus or type 1 diabetes) [7]. Type-1 diabetes and type-2 diabetes share one essential feature: elevated blood sugar (glucose) levels. Based on the World Health Organization (WHO) report, the incidence of diabetes affects more than 170 million persons worldwide. It was recently projected that the total number of people with diabetes will reach 366 million by the year 2030 [8]. As the complication progresses, tissue or vascular damage ensues leading to severe diabetic complications such as retinopathy, neuropathy, nephropathy, cardiovascular complications and ulceration $[9,10]$. However, diabetes covers a wide range of heterogeneous diseases $[11,12]$.

Alstonia boonei (apocynaceae) is a large perennial herb that grows abundantly in West Africa. It is commonly known as God's tree, and used universally for its medicinal properties [13]. It contains several hundred valuable compounds and new constituents are still under investigation [13]. In traditional medicine, it is used as therapy against hypertension and several intestinal diseases with little scientific basis. Joseph et al. [14] and Fabiyi et al. [13] reported the anti-diabetic (hypoglycaemic) property of stool wood (God's tree). It is also recommended by the traditional healers in West Africa for use as analgesic [15]. Therapeutically, the stem bark was found to possess antirheumatic, anti-inflammatory and anti-helminthic properties [15]. The extract from Alstonia boonei has also been reported to reduce the uptake of cholesterol from the gut $[10,16]$.

Additionally, numbers of phytochemicals have been shown to inhibit COX-2 gene in vivo models of carcinogenesis [17]. Inducible nitric oxide synthase (iNOS) also causes the overproduction of nitric oxide during inflammation and tumorigenesis [18]. Hence, repression of the induction and activity of COX-2 and/or iNOS was regarded as novel concept in cancer prevention in many organs [19]. Although, several experimental studies have established the anti-diabetic effect

*Corresponding author: Akintunde Jacob Kehinde, Faculty of Public Health Toxicology and Safety Unit, Department of Environmental Health Sciences, College of Medicine, University of Ibadan, Nigeria, Tel: +23408064156056; E-mail: akintundejacob@yahoo.com

Received November 05, 2016; Accepted November 18, 2016; Published November 25, 2016

Citation: Kehinde AJ, Adebayo AJ, Oluwadamilola SO, Arinola AA (2016) Stem Bark Extract from Alstonia boonei attenuates Cholesterol, Triglyceride and Oxidative Damage via Low Immunohistochemical Expression in Small Intestinal Tract of Male Rats. J Diabetes Metab 7: 715. doi: 10.4172/2155-6156.1000715

Copyright: @ 2016 Kehinde AJ, et al. This is an open-access article distributed under the terms of the Creative Commons Attribution License, which permits unrestricted use, distribution, and reproduction in any medium, provided the original author and source are credited. 
Citation: Kehinde AJ, Adebayo AJ, Oluwadamilola SO, Arinola AA (2016) Stem Bark Extract from Alstonia boonei attenuates Cholesterol, Triglyceride and Oxidative Damage via Low Immunohistochemical Expression in Small Intestinal Tract of Male Rats. J Diabetes Metab 7: 715. doi: $10.4172 / 2155-6156.1000715$

Page 2 of 7

of many antioxidants $[13,14,20]$; but no significant study to the best of our knowledge had demonstrated the relationship between endohypercholesterolemia and small intestinal inflammatory response in diabetic induced rats. Thus, the aim of the present study was to evaluate the effect of PUFAs from SBEAB on two key lipid profile (total cholesterol and triglyceride level), regulation of COX-2 and iNOS expression from STREP-induced diabetic rats.

\section{Materials and Methods}

\section{Sample selection}

Fresh sample of stem bark of Alstonia boonei was purchased from the local market, in Ota metropolis, Ogun State, Nigeria. Authentication of the plant was carried out in the Department of Biology, University of Ibadan, Nigeria. Adult male wistar strain albino rat was purchased from the Biochemistry Department animal colony, University of Ibadan, Nigeria and maintained ad libitum on commercial diet and water.

\section{Chemicals and reagents}

STREP was purchased from Sigma Chemical Co. (St Louis, MO, USA). Rabbit polyclonal COX-2 and iNOS antibodies were products of Cayman Chemical Co. (Ann Arbor, MI, USA). Bovine Serum Albumin (BSA), hydrogen peroxide, trichloroacetic acid (TCA) and thiobarbituric acid (TBA) were purchased from Sigma (St Louis, MO, USA). All the kits used for the bioassay were sourced from Randox Laboratories Ltd. (Crumlin, Dublin, Northern Ireland, UK). All other reagents used were in the purest form available commercially.

\section{Extraction of stem bark Alstonia boonei}

The bark of the stem was thoroughly washed in distilled water to remove any contaminant, chopped into small pieces before being milled. The ethanol extract of the stem was subsequently prepared by soaking the grinded sample $(10 \mathrm{~g})$ in ethanol $(200 \mathrm{~mL})$ for about $24 \mathrm{~h}$ at $37^{\circ} \mathrm{C}$; the mixture was filtered and the filtrate was concentrated by rotator evaporator; designated as $\mathrm{SBEAB}$ and stored in the refrigerator for subsequent analysis.

\section{Animal treatment}

Adult male Wistar rats (200-300 g) from the Central Animal House of the Bells' University of Technology, Ota, Nigeria were used in this experiment. The animals were maintained at a constant temperature $\left(22 \pm 2^{\circ} \mathrm{C}\right)$ on a $12 \mathrm{~h} \mathrm{light/dark} \mathrm{cycle} \mathrm{with} \mathrm{free} \mathrm{access} \mathrm{to} \mathrm{food} \mathrm{and} \mathrm{water.}$ Animal care and handling was done according to the institutional guidelines of Nigeria Academy. The ethical conduct of research involving animals were follow.

\section{Experimental protocol}

The rats were acclimatized for two weeks and randomly divided into five groups of eight animals each $(\mathrm{n}=8)$. Group 1 (Control): serve as the normodiabetic control group; Group 2 (Induced): serve as the diabetics group induced with STREP plus NAD (STREP+NAD); Group 3 (STREP+METAG+NAD): serve as the positive control induced with STREP plus METAG (antidiabetic drug) plus NAD; Group 4 (Pre-treatment): serve as diabetic group pre-treated with $200 \mathrm{mg} / \mathrm{kg}$ body weight of Alstonia boonei extract (SBEAB before+NAD+STREP after) [21]; Group 5 (Post-treatment): serve as diabetic group posttreated with $200 \mathrm{mg} / \mathrm{kg}$ body weight of Alstonia boonei extract(SBEAB after+NAD+STREP before). $120 \mathrm{mg} / \mathrm{kg}$ body weight of nicotinamide (NAD), $80 \mathrm{mg} / \mathrm{kg}$ body weight of streptozotocin and $5 \mathrm{mg} / \mathrm{kg}$ body weight of metaglomide (METAG) were used. In the normodiabetic groups, the animals received water by gavage throughout the entire experiment to be subjected to the same stress (normodiabetic groups). The experiment lasted for two weeks (14 days).

\section{Diabetic determination}

The animals were subjected to overnight fast prior to the induction of diabetes. Streptozotocin (STREP) freshly prepared in citrate buffer $(0.01 \mathrm{M}, \mathrm{pH} 4.5)$. Rats in groups 2,3,4 and 5 received a single intraperitoneal dose of STREP $(80 \mathrm{mg} / \mathrm{kg})$ for $72 \mathrm{hr}$ [22]. Blood samples were taken by tail vein puncture and glucose levels was monitored using automatic auto-analyzer (Fine test Auto-coding ${ }^{\mathrm{TM}}$ ). Animals with blood glucose $\geq 200 \mathrm{mg} / \mathrm{dl}$ after $72 \mathrm{~h}$ were considered diabetic and were used in the study. The non-diabetic animal received $1 \mathrm{ml}$ of $0.1 \mathrm{M}$ citrate buffer intraperitoneally. During the experiment, fasting blood glucose was monitored at 3 days interval. The blood was rapidly collected by direct heart puncture and the liver and testes were isolated, rinsed in cold saline $(0.9 \%)$ and homogenized in phosphate buffer ( $\mathrm{pH}$ 7.4). The protective effect of Alstonia boonei on STREP-induced diabetic was compared to that of metaglomide $(5 \mathrm{mg} / \mathrm{kg}$ ) which has been confirmed to have antidiabetic effects [20]. At the end of each experiment, rats were sacrificed by cervical dislocation. Blood was collected by heart puncture for serum isolation. Small intestine was excised, rinsed in physiological saline and stored at $4^{\circ} \mathrm{C}$ until use for histopathology and immunehistochemistry.

\section{Measurement of cholesterol and triglyceride}

The relevant lipid profiles; cholesterol and triglyceride were measured using commercially available kits (Randox Laboratories Kits, St Louis, MO, USA) according to the manufacturer's guideline.

\section{Determination of lipid peroxidation and catalase activity}

Lipid peroxidation was assessed in terms of malondialdehyde (MDA) formation in the rat liver 10,000 g supernatant fractions. The measurement of thiobarbituric acid reacting substances (TBARS) was performed as described previously [23]. MDA was quantitated in nmole/mg protein. The estimation of catalase (CAT) activity using hydrogen peroxide as substrate was measured according to the method of Clairborne [24]. Protein concentration was determined by the method of Lowry et al. [25].

\section{Histological study and immunohistochemical staining}

Small intestine specimen was fixed in 10\% neutral buffered formalin, embedded in paraffin, and sectioned. After deparaffinization and dehydration, the paraffin blocks were stained with hematoxylin and eosin for microscopic examination. For immunohistochemical analysis, the enzymatic activity of endogenous peroxidases in the liver section was first blocked with $3 \%$ hydrogen peroxide, followed by incubation with rabbit polyclonal anti rat COX-2 antibody (Cayman Chemical CO., Ann Arbor, MI, USA) at room temperature for 40 min. The peroxidase binding sites were detected by staining with 3 , 3'-diaminobenzidine tetrahydrochloride (Dako, Glostrup, Denmark). Finally counterstaining was performed using Mayer's hematoxylin.

\section{Statistical analysis}

The data in each group were expressed as mean \pm standard deviation. A one way analysis of variance (ANOVA) was used to analyze the results and Duncan multiple test was used for the post hoc [26]. Statistical package for Social Science (SPSS) 17.0 for windows was used for the analysis and the least significance difference (LSD) was accepted at $P<0.05$. 
Citation: Kehinde AJ, Adebayo AJ, Oluwadamilola SO, Arinola AA (2016) Stem Bark Extract from Alstonia boonei attenuates Cholesterol, Triglyceride and Oxidative Damage via Low Immunohistochemical Expression in Small Intestinal Tract of Male Rats. J Diabetes Metab 7: 715. doi: $10.4172 / 2155-6156.1000715$

Page 3 of 7

\section{Results}

The GC-MS spectrum of SBEAB contains 18 PUFAs with predominant occurrence of 1, 2-epoxycyclooctane, trans-2-nonenal, 1-(2-hydroxyl-1-nitroethyl) cyclohexanol and Spiro [1,3-dioxolane-2, 2 '-6 6,7$]$ diazobicyclo [3.2.2 non-6-ene (result not shown).

The protective effect of SBEAB on diabetic-induced intestinal injury was evaluated by determining the levels of MDA. As shown in Figure 1, SBEAB pre and post-treatment as well as metaglomide (anti-diabetic drug) significantly $(\mathrm{P}<0.05)$ lowered the level of MDA production in diabetic rats which indicate the end point of intestinal oxidative damage. In addition, there was a significant decrease in intestinal CAT activity of diabetic-induced rats (Figure 2). Histological examination of the small intestine also was in line with the above interpretation. Thus, small intestine specimens from diabetic rats showed inflammatory cellular aggregates in the cryptal regions with loss of some numbers of villi and their tips (Figures $3 \mathrm{~A}$ and $3 \mathrm{~B}$ ) when compared with the control intestines (Figures $3 \mathrm{C}-3 \mathrm{E}$ ). In metaglomide, SBEAB pre and posttreated rats, the cellular membrane of the villial cells was moderately not compromised (Figures 3C and 3E).

The cholesterol level, indicator of inducible hypercholesterolemia was significantly $(\mathrm{p}<0.05)$ higher in diabetic rats when compared with the control group (Figure 4). The remarkable hike level of cholesterol was extensively reduced by metaglomide, SBEAB pre and posttreatment in diabetic-induced animals (Figure 4). Similarly, the level of triglyceride (Figure 5) was significantly $(\mathrm{p}<0.05)$ increased in diabetic rats relative to control animals. The increased level of triglyceride was significantly $(\mathrm{p}<0.05)$ up-turned low after metaglomide, pre and posttreatment with SBEAB (Figure 5).

The protein expression of iNOS and COX-2 were evaluated in small intestine of diabetic rats by immunohistochemistry. As shown in Figures 6 and 7 respectively, both proteins were highly expressed in diabetic rats when compared to the control. However, metaglomide, SBEAB pre and post-treatment decreased the expression of intestinal COX-2 and iNOS proteins in diabetic induced rats. The inhibition of COX-2 and iNOS expression in the small intestine of diabetic rats by SBEAB pre and post-treatment were efficacious than the reference anti diabetic drug-metaglomide (Table 1).

\section{Discussion}

The process of lipid peroxidation steals electrons from lipids in cell membrane causing unrestrained production of free radicals to

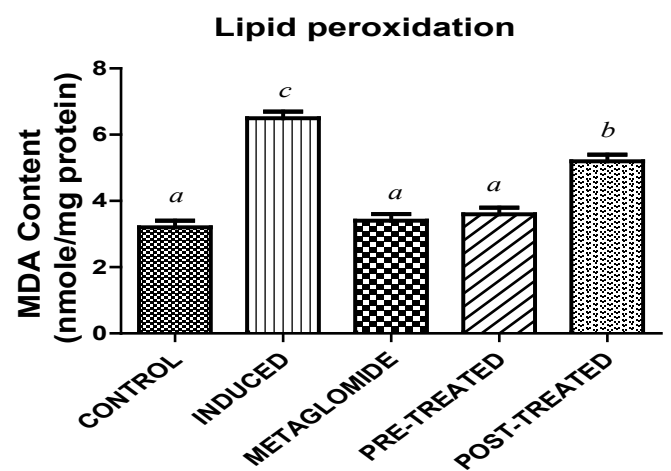

Figure 1: Malondialdehyde (MDA) level from small intestine in diabeticinduced rats treated with stem bark extract Alstonia boonei. Data are presented as mean $\pm S D(n=8)$. Bars with different letters are statistically different.

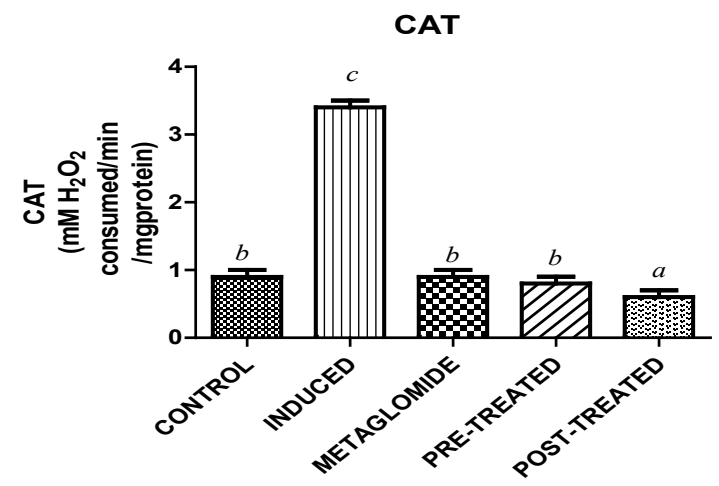

Figure 2: Catalase activity from small intestine in diabetic-induced rats treated with stem bark extract Alstonia boonei. Data are presented as mean \pm $\mathrm{SD}(n=8)$. Bars with different letters are statistically different.

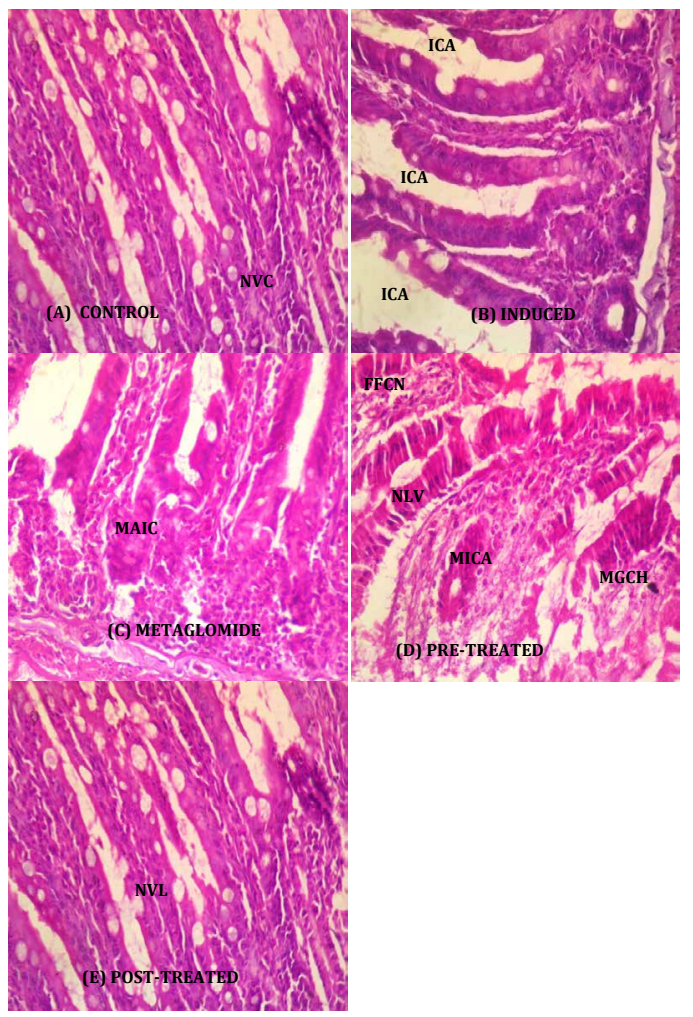

Figure 3: Changes of intestinal villi histopathology in diabetic rat mode (Original magnification X 100) (a) Rats showed normal no visible lesions to the intestinal wall cells i.e normal villi cells (NVC). (b) Diabetic rat intestine showed inflammatory cellular aggregates (ICA) in the cryptal regions with loss of some numbers of villi and their tips (c) Rats treated with metaglomide (anti-diabetic drug) depicted moderate aggregates of inflammatory cells (MAIC) in the cryptal areas and at the base of the villi with numerous tall villi which are mildly sloughed off at the tips (d) Pre-treated group of animals with the SBEAB demonstrated few foci of cryptal necrosis (FFCN), numerous long villi (NLV), moderate inflammatory cellular aggregates (MICA) at the base and lamina propria of villi and moderate goblet cell hyperplasia (MGCH) (e) Post-treated group of animals with SBEAB showed no visible lesion (NVL) with numerous long villi and marked goblet cell hyperplasia. Also, normal and numerous crypts were seen.

initiate cell damage [27]. It usually affects polyunsaturated fatty acids, because they contain multiple double bonds in between the methylene $-\mathrm{CH}_{2}$ - groups [28]. The present study revealed significant increase 
Citation: Kehinde AJ, Adebayo AJ, Oluwadamilola SO, Arinola AA (2016) Stem Bark Extract from Alstonia boonei attenuates Cholesterol, Triglyceride and Oxidative Damage via Low Immunohistochemical Expression in Small Intestinal Tract of Male Rats. J Diabetes Metab 7: 715. doi: $10.4172 / 2155-6156.1000715$

Page 4 of 7

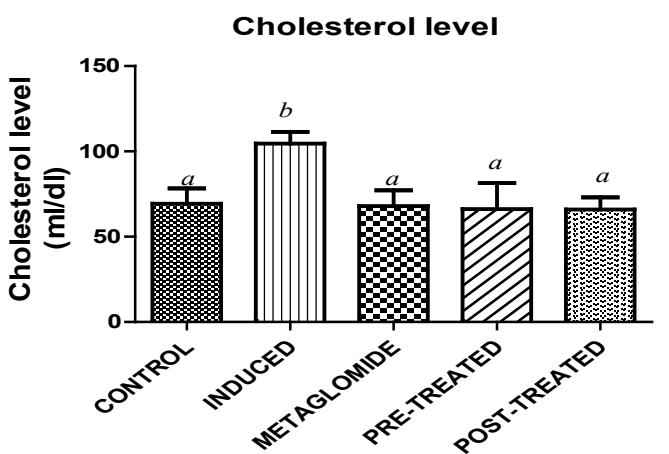

Figure 4: Effect of stem bark extract Alstonia boonei on cholesterol levels in diabetic-induced male rats. Data are presented as mean $\pm S D(n=8)$. Bars with different letters are statistically different.

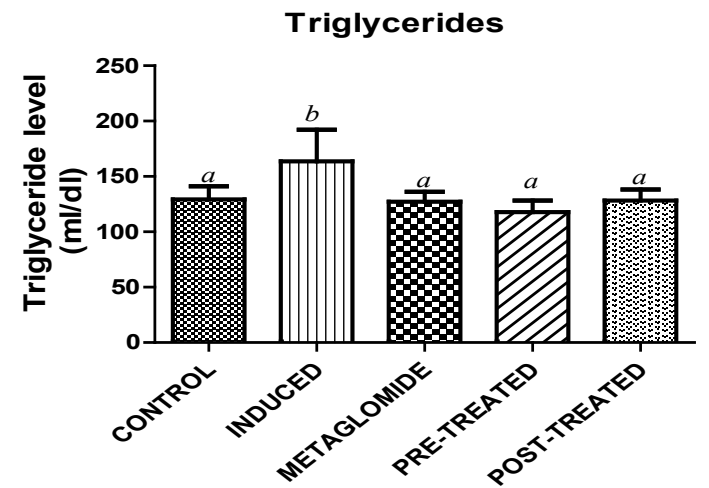

Figure 5: Effect of stem bark extract Alstonia boonei on triglyceride level in diabetic-induced male rats. Data are presented as mean $\pm \operatorname{SD}(n=8)$. Bars with different letters are statistically different.

in small intestinal MDA contents of diabetic induced rat. This result corroborates the previous investigations that patients that were diabetic had abnormal cell membrane [29] and high production of free radicals [30]. However, combined PUFAs from stem bark Alstonia boonei and anti-diabetic drug (METAG) caused a significant low production of MDA content in diabetic-induced rats. This is substantiated by recent studies that African herbs could modulate the oxidative damage in diabetic patients [31-33]. Also, the increased activity of CAT in diabetic animals was significantly ameliorated. This indicates that oxidative stress induced in diabetic rats was reversed by the presence of essential active compounds in the SBEAB. The reversal effect was supported by several findings in which administration of mixed PUFAs from crude extract in experimental animal model was reported as anti-diabetic agents $[34,35]$.

In addition, studies have shown that phytochemicals such as PUFAs inhibit the activities of 3-hydroxyl-3-methylglutaryl CoA reductase (HMG-CoA reductase. This is the committed step in the cholesterol biosynthesis in the liver [36,37] and also intestinal acyl CoA; cholesterol acyltransferase (ACAT). These enzymes play a significant role in the absorption of cholesterol by esterification of cholesterol prior to absorption [37]. As observed from the present study, there was a significant rise in plasma cholesterol and triglyceride contents in diabetic induced rat. This observation agrees with previous studies where individuals suffering from type 1 diabetes depicted increased cholesterol and abnormal LDL-cholesterol level $[38,39]$. It was also reported that diabetic patients are more predisposed to colon and intestinal cancer [40]. In addition, molecular pathophysiological mechanism of hyperglycemia and hypercholesterolemia revealed alterations in lipid and amino acid metabolism [41]. However, the remarkable high level of cholesterol and triglycerides were considerably reversed by an anti-diabetic drug (metaglomide), SBEAB pre and post-treatment in diabetic-induced animals. The preventive mechanism of SBEAB pre-treatment was most efficacious in combating hypercholesterolemia in diabetic induced rats followed by SBEAB posttreatment and metaglomide respectively. This suggests that inhibition of cholesterol synthesis was responsible for the hypocholesterolemic effect by the combined PUFAs from stem bark extract of Alstonia boonei (SBEAB) in diabetic induced rat. Also, polyphenols are released at various points of the gastrointestinal tract (GIT) where they exert their beneficial effects [42]. Hypercholesterolemia in type-1 diabetes had been a major risk factor in the progression of cardiovascular diseases such as, atherosclerosis, myocardial infarction, heart attacks and cerebro-vascular diseases [39]. These disease conditions were implicated in death of people in many countries of the world [41]. And, lowering the plasma cholesterol levels has been demonstrated to reduce the risk of these diseases [38]. This further suggests that PUFAs from Alstonia boonei could improve the body cholesterol homeostasis.

Pathologically, intestines from diabetic rats revealed inflammatory

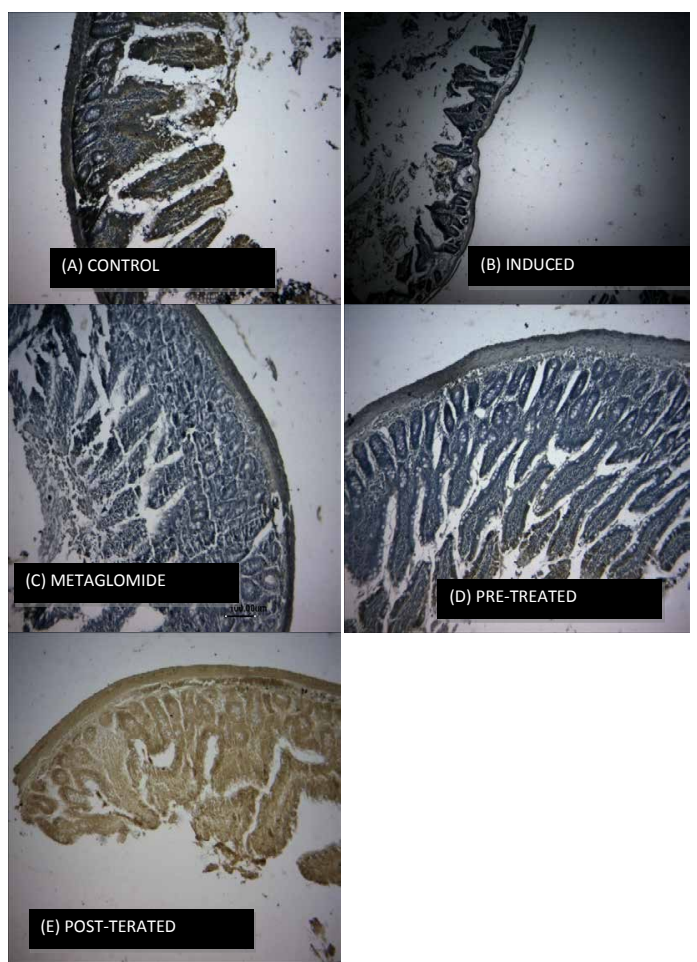

Figure 6: Effect of dietary differential supplementation of Alstonia boonei on intestinal cyclooxygenase-2 (COX-2) expression in diabetic induced rats: (a) No visible expression of COX-2 (NVEC) i.e. the villi were intact and normal architectural structures of the membrane were observed. (b) Battered or eroded villi with distorted architectural structure of both membrane and internal parts in diabetic induced rats were seen, signifying the expression of COX-2 (SEC). (c) There was little expression of COX-2 (LEC) which resulted into mild distortion of the villi without distorted membrane architecture (d) No visible expression of COX-2 (NVEC) i.e there were intact and normal architectural structures of the membrane and the villi were not affected. (e) Also, this group showed no visible expression of COX-2 (NVEC). There were intact and normal architectural structures of the membrane and the villi were not affected. 
Citation: Kehinde AJ, Adebayo AJ, Oluwadamilola SO, Arinola AA (2016) Stem Bark Extract from Alstonia boonei attenuates Cholesterol, Triglyceride and Oxidative Damage via Low Immunohistochemical Expression in Small Intestinal Tract of Male Rats. J Diabetes Metab 7: 715. doi: $10.4172 / 2155-6156.1000715$

Page 5 of 7

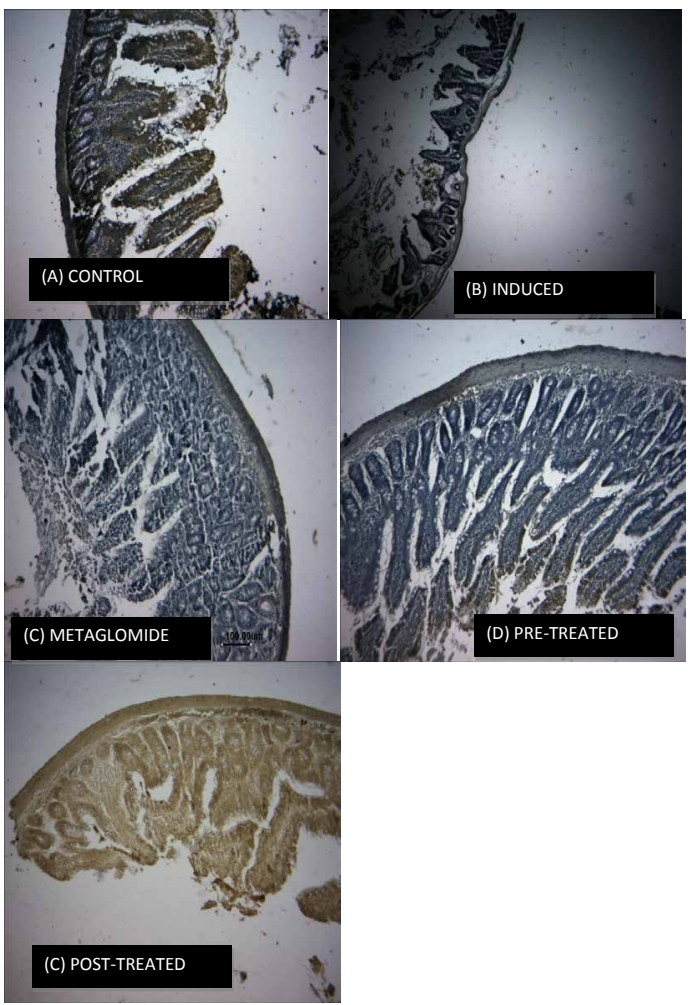

Figure 7: Effect of differential treatment of Alstonia boonei on small intestinal inducible nitric oxide synthase (iNOS) expression in diabetic induced rats: (a) No visible expression of iNOS (NVEI) i.e. the villi were intact and normal architectural structures of the membrane were observed (b) Battered or eroded villi with distorted architectural structure of both membrane and internal parts in diabetic induced rats were seen, signifying the expression of iNOS (SEI). (c) There was little expression of iNOS (LEI) which resulted into mild distortion of the villi without distorting membrane architecture (d) No visible expression of iNOS (NVEI) i.e. there were intact and normal architectural structures of the membrane and the villi were not affected. (e) Also, this group showed no visible expression of iNOS (NVEI). There were intact with normal architectural structures of the membrane and the villi were not affected.

\begin{tabular}{|c|c|c|}
\hline Treatment & iNOS & COX-2 \\
\hline Control & 0 & 0 \\
\hline Induced & 2 & 2 \\
\hline Metaglomide & 1 & 1 \\
\hline Pre-treatment & 0 & 0 \\
\hline post-treatment & 1 & 0 \\
\hline
\end{tabular}

iNOS, inducible nitric oxide synthase; COX-2, cyclooxygenase-2. Key to scores: $0=$ No intestinal cancer formation, $1=$ =mild intestinal cancer formation, $2=$ severe intestinal cancer formation. Pre and post-treatment are more efficacious in preventing small intestinal cancer in diabetic rats than METAG-treatment (pre=post>METG).

Table 1: Scoring of differential protective effect of stem bark extract Alstonia boonei and metaglomide on iNOS and COX-2 expression in small intestine of diabetic induced rats.

cellular aggregates in the cryptal regions with loss of some numbers of villi when compared with the control intestines. This discovery suits the recent investigation which reported that necrotic lesions of the intestinal cells (ileum, duodenum, jejunum etc.) was responsible for the abnormal or reduced absorption of cholesterol [43] which could lead to complicated hypercholesterolemia and its associated difficulties. Also, another work reported that chronic inflammations of villi are preponderantly manifested in diabetic patients than disease- free individuals [44]. This also suggests that the crucial pathway for maintaining cholesterol homeostasis between blood and peripheral tissues had been disrupted $[45,46]$. The villial cells of animal group pre and post treated with SBEAB were reasonably preserved. Absolutely, pre-treatment with $\mathrm{SBEAB}$ is most efficacious to safeguard intestinal cells in diabetic rat followed post-treatment and anti-diabetic drug (METAG) respectively. This action may be linked to the synergistic, competitive and mutual functionality of the PUFAs in the stem bark of Alstonia boonei [47].

Furthermore, due to oxidative stimulus and intestinal carcinogenic insult in diabetic patient, we investigate the effect of SBEAB on the regulation of COX-2 and iNOS expression. It has been reported that activation of several transcription factors were involved in the regulation of iNOS and COX-2 expression [17]. As revealed from the study, pre and post treatment with Alstonia boonei abrogated the expressions of COX-2 and iNOS genes in the small intestine of diabetic-induced rat. Togetherness, we report that pre and posttreatment are more efficacious in combating pro-inflammation and/ or cancer of the small intestine in diabetic rats rather than METAGadministration. The result therefore proposed that combined PUFAs from SBEAB would be novel intestinal anti-transcription factors. This report validates the previous studies which suggested that active components from plant origin are strong inhibitor of transcription factors linked to carcinogenesis [17,48]. Also, several experimental studies have demonstrated the antioxidant, anti-hepatotoxic and antigenotoxic properties of phenolic compounds in various experimental models [49-51]. However, in the present study, we report that PUFAs from $\mathrm{SBEAB}$ as endogenous hypocholesterolemic agents and inhibitors of COX-2 and iNOS expression in the small intestinal tract of diabetic rat.

\section{Conclusion}

Essentially, PUFAs from Alstonia boonei depleted the level of plasma cholesterol and triglycerides with corresponding decrease in MDA levels of the small intestine in diabetic induced rat. The activity of enzymatic antioxidant- CAT was significantly elevated in diabetic induced rat; indicator of oxidative stress. The hike activity was reversed in animal group treated with SBEAB. Also, animals exposed to SBEAB showed reasonable preservation of the intestinal villi. Pre and posttreatment are better to prevent pro-inflammatory response and intestinal cancer in diabetic rats rather than METAG-administration. Taken together, the inhibition of genes encoding COX-2 and iNOS proteins suggest the molecular mechanism of the small intestine protection by SBEAB and further advocates the links between the malabsorption of cholesterol and diabetic individuals.

\section{Compliance with Ethical Standards}

All applicable international, national, and/or institutional guidelines for the care and use of animals were followed. This study was not funded by any organisation or institution that may influence the work.

\section{Disclosure of Potential Conflict of Interest}

Akintunde Jacob Kehinde declares that he has no conflict of interest. Ajiboye John Adebayo also declares that he has no conflict of interest. Soyinka Oluwadamilola equally declares that she has no conflict of interest. Similarly, Adeyemi Arinola declares that she has no conflict of interest. 
Citation: Kehinde AJ, Adebayo AJ, Oluwadamilola SO, Arinola AA (2016) Stem Bark Extract from Alstonia boonei attenuates Cholesterol, Triglyceride and Oxidative Damage via Low Immunohistochemical Expression in Small Intestinal Tract of Male Rats. J Diabetes Metab 7: 715. doi: $10.4172 / 2155-6156.1000715$

Page 6 of 7

\section{Informed Consent}

Informed consent was not applicable because the study did not involve human participants.

\section{References}

1. Nelson LD, Cox MM, Freeman WH (2008) Lehninger Principles of Biochemistry: Protein function and Company. New York Press 355: 836-845

2. Wang YM, Zhang B, Xue Y, Li ZJ, Wang JF, et al. (2010) The mechanism of dietary cholesterol effects on lipids metabolism in rats. Lipids Health Dis 9: 4.

3. Hyogo H, Chayama K, Yamagishi S (2014) Nonalcoholic fatty liver disease and cardiovascular disease. Curr Pharm Des 20: 2403-2411.

4. Streba LA, Vere CC, Rogoveanu I, Streba CT (2015) Nonalcoholic fatty liver disease, metabolic risk factors, and hepatocellular carcinoma: an open question. World J Gastroenterol 21: 4103-4110.

5. Martín-Timón I, Sevillano-Collantes C, Segura-Galindo A, Del Cañizo-Gómez FJ (2014) Type 2 diabetes and cardiovascular disease: Have all risk factors the same strength? World J Diabetes 5: 444-470.

6. Al-Rawahi A, Lee P (2015) Applicability of the Existing CVD Risk Assessment Tools to Type II Diabetics in Oman: A Review. Oman Med J 30: 315-319.

7. Fu AZ, Qiu Y, Radican L, Yin DD, Mavros P (2014) Pre-existing cardiovascular diseases and glycemic control in patients with type 2 diabetes mellitus in Europe: a matched cohort study. Cardiovasc Diabetol 9: 15.

8. Shaw JE, Sicree RA, Zimmet PZ (2010) Global estimates of the prevalence of diabetes for 2010 and 2030. Diabetes Res Clin Pract 87: 4-14.

9. Cade WT (2008) Diabetes-related microvascular and macrovascular diseases in the physical therapy setting. Phys Ther 88: 1322-1335.

10. Tiwari BK, Pandey KB, Abidi AB, Rizvi SI (2013) Markers of Oxidative Stress during Diabetes Mellitus. J Biomark 37: 87-90.

11. Akintunde JK, Oboh G (2013) Municipal Auto-Battery Recycling-Site Leachate Activates Key Enzymes Linked to Non-Insulin Dependent Diabetes Mellitus (NIDDM) and Hypertension. J Diabetes Metab 4: 235

12. Babizhayev MA, Strokov IA, Nosikov VV, Savel'yeva EL, Sitnikov VF, et al. (2013) The Role of Oxidative Stress in Diabetic Neuropathy: Generation of Free Radical Species in the Glycation Reaction and Gene Polymorphisms Encoding Antioxidant Enzymes to Genetic Susceptibility to Diabetic Neuropathy in Population of Type I Diabetic Patients. Cell Biochem Biophys 25: 885-889.

13. Fabiyi OA, Atolani O, Olatunji GA (2012) Nematicidal activity of Alstonia boone and bridelia ferruginea leaves Albanian. j agric Sci 11: 2218-2020

14. Maroon JC, Bost JW, Maroon A (2010) Natural anti-inflammatory agents for pain relief. Surg Neurol Int 1: 80.

15. Adotey JP, Adukpo GE, Boahen YO, Armah FA (2012) A Review of the Ethnobotany and Pharmacological Importance of Alstonia boonei De Wild (Apocynaceae). ISRN Pharmacol 5: 160-174.

16. Fakae BB, Campbell AM, Barrett J (2000) Inhibition of glutathione S-transferases (GSTs) from parasitic nematodes by extracts from traditional Nigerian medicinal plants. Phytotherapy Research 14: 630-634.

17. Farombi EO, Shrotriya S, Surh YJ (2009) Kolaviron inhibits dimethy nitrosamine-induced liver injury by suppressing COX-2 and iNOS expression via NF-kappaB and AP-1. Life Sci 84: 149-155.

18. Mami T, Tsukasa K, Rikako I, Michihiro M, Masami K, et al. (2008) Increased expression of inducible nitric oxide synthase (iNOS) in N-nitrosobis (2-oxopropyl) amine-induced hamster pancreatic carcinogenesis and prevention of cancer development by ONO-1714, an iNOS inhibitor. Carcino 29: 1608-1613.

19. Choudhari SK, Chaudhary M, Bagde S, Gadbail AR, Joshi V (2013) Nitric oxide and cancer: a review. World J Surg Oncol 11: 118.

20. Akinloye OA, Oshilaja RT, Okelanfa OA, Akinloye DI, Idowu OM (2013) Hypoglyceamic activity of Alstonia boonei stems bark extract in mice. Agric Biol J N Am 4: 1-5.

21. Onifade OF, Maganda V (2015) In Vivo Activity of Ethanolic Extract of Alstonia Boonei Leaves against Plasmodium Berghei in Mice. JWHSD 1: 60-68.

22. Milani E, Nikfar S, Khorasani R, Zamani MJ, Abdollahi M (2005) Reduction of diabetes-induced oxidative stress by phosphodiesterase inhibitors in rats. Compar Biochem \& Physiol 140: 251-255.

23. Ohkawa H, Ohishi N, Yagi K (1979) Assay for lipid peroxides in animal tissues by thiobarbituric acid reaction. Anal Biochem 95: 351-358.

24. Clairborne AI (1995) Catalase activity. In: Greewald AR, editor.Handbook of methods for oxygen radical research. Florida: CRC Press 22: 237-242.

25. Lowry OH, Rosebrough NJ, Farr AL, Randall RJ (1951) Protein measurement with the Folin phenol reagent. J Biol Chem 193: 265-275

26. Zar JH (1984) Biostatistical Analysis, Prentice-Hall. International USA 620.

27. Akintunde JK, Oboh G, Akindahunsi AA (2013) Testicular membrane lipid damage by complex mixture of leachate from municipal battery recycling site as indication of idiopathic male infertility in rat. Interdisci Toxicol 6:192-197.

28. Mohammad EEE, Amal AAA (2015) Can vitamin C affect the KBrO3 induced oxidative stress on left ventricular myocardium of adult male albino rats? A histological and immunohistochemical study. Jour of Micro and Ultrastr 3: 120 136

29. Saba AB, Oyagbemi AA, Azeez OI (2010) Antidiabetic and haematinic effects of Parquetina nigrescens on alloxan induced type-1 diabetes and normocytic normochromic anaemia in Wistar rats. Afr Health Sci 10: 276-282.

30. Orrio N, Sirovina D, Gajski G, Garaj-Vrhovac V, Jembrek MJ, et al. (2013) Assessment of DNA damage and lipid peroxidation in diabetic mice: effects of propolis and epigallocatechin gallate (EGCG). Mutat Res 757: 36-44.

31. Khan V, Najmi AK, Akhtar M, Aqil M, Mujeeb M, et al. (2012) A pharmacologica appraisal of medicinal plants with antidiabetic potential. J Pharm Bioallied Sci 4: $27-42$.

32. George GS, Uwakwe AA, Ibeh GO (2013) Antioxidant Properties of Some Local Herbs Extract On STZ-Induced diabetics Rats. Sch. J App Med Sci 1: 301-303.

33. Cicero LTC, Yenshou L, Arlene PB, Yi-Ching C, Shao-Chih C, et al. (2013) Herbal Therapies for Type 2 Diabetes Mellitus: Chemistry, Biology, and Potential Application of Selected Plants and Compounds. Evidence-Based Comple and Alter Med 22: 1-33.

34. Al-Attar AM, Zari TA (2010) Influences of crude extract of tea leaves, Camellia sinensis, on streptozotocin diabetic male albino mice. Saudi J Biol Sci 17: 295301.

35. Haidari F, Shahi MM, Zarei M, Rafiei H, Omidian K (2012) Effect of green tea extract on body weight, serum glucose and lipid profile in streptozotocininduced diabetic rats. A dose response study. Saudi Med J 33: 128-133.

36. Vanitha RP, Asna U (2014) Inhibition of 3-Hydroxy-3-methylglutaryl Coenzyme A Reductase (Ex Vivo) by Morus indica (Mulberry). Chin Jour of Biol 2: 1-5.

37. Baskaran G, Salvamani S, Ahmad SA, Shaharuddin NA, Pattiram PD, et al. (2015) HMG-CoA reductase inhibitory activity and phytocomponent investigation of Basella alba leaf extract as a treatment for hypercholesterolemia. Drug Des Devel Ther 9: 509-517.

38. Guenther S, Guenter F, Michael MH, Dieter L, Bernhard RW, et al. (2010) The associations of cholesterol metabolism and plasma plant sterols with all-cause and cardiovascular mortality. J Lipid Res 51: 2384-2393.

39. Lupattelli G, De Vuono S, Mannarino E (2011) Patterns of cholesterol metabolism: pathophysiological and therapeutic implications for dyslipidemias and the metabolic syndrome. Nutr Metab Cardiovasc Dis 21: 620-627.

40. Vigneri P, Frasca F, Sciacca L, Pandini G, Vigneri R (2009) Diabetes and cancer. Endocr Relat Cancer 16: 1103-1123.

41. Wang TJ, Larson MG, Vasan RS, Cheng S, Rhee EP, et al. (2011) Metabolite profiles and the risk of developing diabetes. Nat Med 17: 448-453.

42. Oboh G, Puntel RL, Rocha JBT (2007) Hot pepper (Capsicum annuum, Tepin and Capsicum chinese, Habanero) prevents $\mathrm{Fe} 2+$-induced lipid peroxidation in Brain - in vitro. Food Chem 102: 178-185.

43. Boris J (2015) Critical Review of Public Health Regulations of Titanium Dioxide a Human Food Additive. Integr Environ Assess Manag 11: 10-20.

44. Mingyi C, Amrita K, Ali RM, Ralph G (2013) Hematological Disorders following Gastric Bypass Surgery: Emerging Concepts of the Interplay between Nutritional Deficiency and Inflammation. BioMed Research Inter 23: 1-8.

45. Daniels TF, Killinger KM, Michal JJ, Wright RW, Jiang Z (2009) Lipoproteins, cholesterol homeostasis and cardiac health. Int J Biol Sci 5: 474-488. 
Citation: Kehinde AJ, Adebayo AJ, Oluwadamilola SO, Arinola AA (2016) Stem Bark Extract from Alstonia boonei attenuates Cholesterol, Triglyceride and Oxidative Damage via Low Immunohistochemical Expression in Small Intestinal Tract of Male Rats. J Diabetes Metab 7: 715. doi: 10.4172/2155-6156.1000715

46. Juan Z, Qiang L (2005) Cholesterol metabolism and homeostasis in the brain. Protein Cell 6: 254-264.

47. Akinyemi JA, Gustavo RT, Vera MM, Naiara S, Pauline da C, et al. (2015) Effect of dietary supplementation of ginger and turmeric rhizomes on ectonucleotidases, adenosine deaminase and acetylcholinesterase activities in synaptosomes from the cerebral cortex of hypertensive rats. J of Appl Biomed 22: $18-26$.

48. Khuda-Bukhsh AR, Das S, Saha SK (2014) Molecular approaches toward targeted cancer prevention with some food plants and their products: inflammatory and other signal pathways. Nutr Cancer 66: 194-205.
49. Rodrigues CR, Dias JH, de Mello RN, Richter MF, Picada JN, et al. (2009) Genotoxic and antigenotoxic properties of Baccharis trimera in mice. J Ethnopharmacol 125: 97-101.

50. Sebastião de OR, Juliana da S, Ricardo SB, Natalia D, Marcela SS, et al (2013) Assessment of the genotoxic and mutagenic properties of Himatanthus Articulates bark extracts used as phytotherapeutic drug in the Amazon. Journal of Ethnopharm 147: 474-480.

51. Stohs SJ, Hartman MJ (2015) Review of the Safety and Efficacy of Moringa oleifera. Phytother Res 29: 796-804. 